\title{
COVID-19 Pandemic and Physical Exercise: Lessons Learnt for Confined Communities
}

\author{
Amine Ghram ${ }^{1,2+}$, Nicola Luigi Bragazzi ${ }^{3 * t}$, Walid Briki ${ }^{4}$, Yaser Jenab ${ }^{5}$, Mehdi Khaled ${ }^{6}$, \\ Monoem Haddad ${ }^{4}$ and Karim Chamari ${ }^{7}$ \\ ${ }^{1}$ Department of Exercise Physiology, Faculty of Physical Education and Sport Sciences, University of Tehran, Tehran, Iran, \\ ${ }^{2}$ Department of Cardiac Rehabilitation, Tehran Heart Center, Tehran University of Medical Sciences, Tehran, Iran, \\ ${ }^{3}$ Laboratory for Industrial and Applied Mathematics, Department of Mathematics and Statistics, York University, Toronto, \\ ON, Canada, ${ }^{4}$ Department of Physical Education, College of Education, Qatar University, Doha, Qatar, ${ }^{5}$ Department \\ of Interventional Cardiology, Tehran Heart Center, Tehran University of Medical Sciences, Tehran, Iran, ${ }^{6}$ Independent \\ Physician (Internal Medicine), Singapore, Singapore, ${ }^{7}$ Aspetar, Qatar Orthopaedic and Sports Medicine Hospital, Doha, \\ Qatar
}

\section{OPEN ACCESS}

Edited by:

Ricardo De La Vega, Autonomous University of Madrid,

Spain

Reviewed by:

Liudmila Liutsko,

Instituto de Salud Global de Barcelona (ISG/obal), Spain Hamdi Chtourou,

University of Sfax, Tunisia

*Correspondence:

Nicola Luigi Bragazzi robertobragazzi@gmail.com

tThese authors have contributed equally to this work and share first authorship

Specialty section: This article was submitted to Movement Science and Sport Psychology, a section of the journal Frontiers in Psychology

Received: 17 October 2020 Accepted: 08 April 2021 Published: 05 May 2021

Citation:

Ghram A, Bragazzi NL, Briki W, Jenab Y, Khaled M, Haddad $M$ and

Chamari K (2021) COVID-19

Pandemic and Physical Exercise:

Lessons Learnt for Confined

Communities.

Front. Psychol. 12:618585. doi: 10.3389/fpsyg.2021.618585
The novel pandemic called "Coronavirus Disease 2019" (COVID-19), as a global public health emergency and global threat, has affected many countries in unpredictable ways and impacted on physical activity (PA) behaviors to various extents. Specific populations including refugees, asylum seekers, and prisoners, are vulnerable groups with multiple complex health needs and worse health outcomes with respect to the general population worldwide and at high risk of death from the "Severe Acute Respiratory Syndrome-related Coronavirus type 2" (SARS-CoV-2). Governments around the world have been implementing preventive healthcare policies, including physical and social distancing, isolation, and confinement, to mitigate against the burden imposed by the COVID-19 outbreak. This pandemic period is characterized by reduced or lack of movement. During this period of lockdown, PA can represent an immunotherapy and a preventative approach to avoid the harmful effects of inactivity due to the pandemic. Moreover, PA could be prescribed to improve the immune system of specific populations (refugees, asylum seekers, and prisoners), which particularly experience the condition of being confined. The present narrative review discusses the potential impacts of COVID-19 pandemic on these specific populations' health status and the importance of performing PAVexercise to reduce the deleterious effects of COVID-19 pandemic. In addition, we aim to provide useful recommendations on PA/exercise for these specific populations to maintain their level of independence, physical, and mental health as well as their wellbeing.

Keywords: coronavirus, physical activity, exercise, incarcerated, prison, health, sedentary

\section{INTRODUCTION}

Viral infections can have a profound effect on human life, in terms of morbidity and fatality rate. One of the most lethal outbreaks in the history of mankind is the 1918-1919 Spanish influenza pandemic (Kain and Fowler, 2019). Even though influenza is a commonly widespread respiratory infection, various serious complications, such as pneumonia, can occur if the disease is not quickly and effectively controlled (Kohut et al., 2004). Worldwide, according to some estimations, seasonal influenza can cause up to 3-5 million cases of severe illness, and result in approximately 
500,000 deaths per year due to the increased susceptibility among populations, especially those vulnerable (Cao et al., 2011). Recently, in late December 2019, a pneumonia outbreak of unknown etiology started in the city of Wuhan (Hubei province, mainland China) and has spread rapidly to neighboring provinces in China and around the world. Human-to-human transmission of the virus, initially denied, has been subsequently acknowledged (Chan et al., 2020). As of February 14, 2021 (15:29 GMT), the total number of confirmed cases has significantly increased up to $109,189,351$ in the world, with 2,407,133 deceased and 81,230,179 recovered. This infection has been named as "Coronavirus Disease 2019" (COVID-19), whereas the infectious agent has been termed as the "Severe Acute Respiratory Syndrome-related Coronavirus type 2" (SARS-CoV-2).

This novel pandemic, as a global public health emergency and a global threat, has affected many countries in unpredictable ways and impacted physical activity (PA) behaviors to various extents. Particularly, people's lifestyles and behaviors, such PA and sedentary behavior (SB) have been drastically affected due to the prolonged closures, isolation/confinement and physical and social distancing practiced during the COVID-19 pandemic. The still ongoing outbreak poses, indeed, challenges for all the population and, in particular, for specific populations including asylum seekers, refugees, and prisoners as the pandemic sweeps across the globe. The spread of the COVID-19 pandemic is threatening people's health and life safety and has critical impact on social life and national economy, at the same time (Wan et al., 2020). The aftermath of such outbreaks does not only harm physical but psychological and social health as well ( $\mathrm{Li}$ S. et al., 2020). The issue has become increasingly relevant as an increasing number of incarcerated individuals test positive for COVID-19 (Stephenson, 2020). People residing in areas characterized by high population density or rural areas with poor access to health care facilities, living in shared or congregate housing and multi-generational households, immigrants, refugees, racial and ethnic minorities are at higher risk for contracting COVID-19 (Ainsworth and Li, 2020). Moreover, multiple wave outbreaks are occurring due to the relaxing/easing of the public health measures implemented and the insurgence of new coronavirus strains racing across many countries (Siu et al., 2020). Being confined, isolated, hospitalized, or incarcerated is likely to compromise human wellbeing. SB (e.g., prolonged sitting or screen time), as a global public health concern, represents a major risk to wellbeing (Katzmarzyk et al., 2009; Dunstan et al., 2010; Ghram et al., 2020a) and is related to the adoption of unhealthy behaviors and lifestyles (e.g., physical inactivity, and dietary habits) (Bao et al., 2020). Thus, decreasing $\mathrm{SB}$, adopting good personal hygiene practices, and regular PA and exercise may be an effective way to counteract/mitigate the detrimental effects of living under restricted environments due to COVID-19 spread. The common saying, "prevention is better than cure," still holds true (Ghram et al., 2020a). Due to the lack of an appropriate antiviral agent and due to the scarcity of vaccine stocks, we need a safe intervention that can be globally implemented (Ramalingam et al., 2020). The European Union (EU), the United States (USA) and Canada, and Australia have significantly invested in sports-related programs and interventions aimed at engaging refugees and asylum seekers in sports-related and physical activities for health, therapeutic, or societal purposes (Spaaij et al., 2019). Indeed, PA and exercise could alleviate and mitigate against the symptoms and enhance the physical and psychological health status of individuals who are confined or incarcerated and exercise prescriptions could provide advice for these specific populations to be involved in suitable physical exercises and activities in order to promote the physical wellness as well as work efficiency (Ghram et al., 2020a). If, on the one hand, PA and exercise may facilitate the virus spread and, as such, should always be practiced under certain circumstances and strictly following the protective measures against COVID-19, on the other hand, PA and exercise might strengthen the immune system that could help to combat COVID-19 in these vulnerable populations (Ghram et al., 2020a; Laddu et al., 2020).

In the present narrative review, we aim to stress the importance of the public health measures that have been enforced to limit the COVID-19 spread and their effects among asylum seekers, refugees, and prisoners. Then, we focus on the risks of being isolated, physical inactivity and SB associated with the novel coronavirus outbreak. Finally, we discuss the consequences of being active, and the potential role of PA/exercise in counteracting the negative effects of the COVID-19 induced lockdown and reducing the risk of developing health problems among specific populations.

\section{WHAT IS COVID-19?}

Coronaviruses are enveloped, single-stranded, positive-sense RNA viruses that generally cause mild respiratory symptoms and occasionally severe and lethal infections (Fehr and Perlman, 2015). In the last decades, several large-scale coronavirusesinduced outbreaks have occurred, including the "Severe Acute Respiratory Syndrome" (SARS) outbreak in China (2003), and the "Middle Eastern Respiratory Syndrome" (MERS) outbreaks in the Kingdom of Saudi Arabia (2012) and in South Korea (2015) (Bok et al., 2020).

The current pandemic caused by SARS-CoV-2 can lead, as previously mentioned, to an usually mild but sometimes life-threatening infection (Wang et al., 2020), like bilateral pneumonia, myocardial injury, respiratory failure, acute respiratory distress syndrome (ARDS), multi-organ failure (MOF) and, in some cases, can even result in death (Holshue et al., 2020). Symptoms at the onset of COVID-19 infection as reported in hospitalized patients in China include fever, cough, fatigue, myalgia, sputum production, dyspnea, oppression in the chest, diarrhea, headache, anorexia, chest pain, sore throat, dizziness, palpitations, and vomiting (Gilani et al., 2020).

\section{MODE AND TRANSMISSION OF THE COVID-19 VIRUS}

Coronavirus Disease 2019 virus is mainly transmitted through respiratory droplets and physical contact routes 
(Burke et al., 2020; Chan et al., 2020; Huang et al., 2020; Li Q. et al., 2020; Liu et al., 2020). Droplet transmission can occur when a subject is in close contact with an individual with respiratory symptoms (e.g., coughing or sneezing) and is at risk of having his/her mucosae (mouth and nose) or conjunctiva (eyes) exposed to potentially infective respiratory droplets. Viral spreading may also occur via fomites surrounding the infected person (Ong et al., 2020).

During the early stages of the outbreak, Africa has shown very few COVID-19 cases compared to the number of cases reported in European and Asian countries, which can be explained by differences in the number of swabs performed, in the largescale testing and reporting, as well as by the low volume of travel connections, enhanced border screening policies and the beneficial impact of Africa's hot climate (Otu et al., 2020).

\section{PREVENTIVE HEALTHCARE MEASURES OF COVID-19 IN THE COMMUNITY}

Due to the highly contagious nature of the virus, it has rapidly spread globally, and many countries are experiencing overwhelmed and strained national health systems. Moreover, they are suffering from shortage of protection devices and human resources needed to adequately treat infected patients (ECDC, 2020). To cope with virus outbreak, the health care authorities have made dreadful decisions. Given the absence of effective therapeutic interventions at the time of the virus global spread, cities and countries have decided to adopt non-pharmacological measures, implementing selfisolation, social distancing, quarantine and even lock-down of entire communities and territories as well as travel restrictions (Wilder-Smith and Freedman, 2020).

According to the "World Health Organization" (WHO), several low-cost non-medical countermeasures that would contain spread have been recommended widely, including personal protective equipment like masks and gloves, reduction in the need for attending crowded public spaces, enhanced hygienic measures like frequent cleaning of door handles and other public surfaces, and similar measures (Bell et al., 2006).

While these measure, on the one hand, have contributed to saving lives, on the other hand, the COVID-19 pandemic is resulting in serious psychological effects such as anxiety, insomnia, panic behavior, fear, and hopelessness (Ammar et al., 2020b, 2021; Chtourou et al., 2020; Khan et al., 2020) and has caused and is still causing a massive economic shock across the world due to business interruptions, disruption and closures due to social-distancing measures (Martin et al., 2020). It was shown that COVID-19 home confinement has a negative effect on social participation and life satisfaction (Ammar et al., 2020a). To prevent viral infection, infected people should isolate themselves, which may increase the stress burden on family members due to the fear of getting infected (Khan et al., 2020).

In other words, preventive measurements during the massive lockdown may increase stress in the general and specific populations. Isolating infected individuals inside homes or jails/prisons may also increase the stress burden on family members due to the fear of getting infected. Indeed, the population must be informed during and after control of the pandemic about the possible impact of the viral outbreak, in terms of individual risk, outcomes of negative health behaviors, to take specific measures to mitigate such detrimental effects. Summarizing, public awareness regarding necessary actions to prevent the spread of a viral infection and counteract its negative impact is of paramount importance (Khan et al., 2020).

\section{COVID-19 OUTBREAK'S IMPACT ON REFUGEES AND ASYLUM SEEKERS}

Asylum seekers and refugees experience severe mental and physical strain (war, violence, political and religious persecution, poverty, imprisonment, torture as well as traumatic and hard living conditions, economic hardship, discrimination, social exclusion, exploitation) (Knappe et al., 2019). People in refugee camps live in a closed environment and in close proximity that facilitate transmission of diseases (WHO, 2020). They also have a greater underlying burden of disease and worse health conditions than the general population, and frequently face greater exposure to risks such as smoking, poor hygiene and weak immune defense due to stress, poor nutrition, or existing diseases (WHO Regional Office for Europe, 2020). People in places of detention should have comprehensive awareness of COVID19 prevention strategies, including adherence to hand hygiene measures, respiratory etiquette (covering coughs and sneezes), practicing physical distancing (at least 1 meter from others), being alert to signs and symptoms of COVID-19, staying away from ill people (in the case of staff), and staying home when ill.

Many asylum seekers have complex mental health needs which can be exacerbated by the challenging circumstances in which they live and difficulties accessing health services (HaithCooper et al., 2018). Refugees have a higher prevalence rate for psychopathological disorders such as post-traumatic stress disorder (PTSD), depression, or anxiety disorders (Gerritsen et al., 2006). All this together makes COVID-19 spreading in world's refugee camps particularly concerning. Millions of displaced people in Bangladesh (Rohingya refugees), Syria (Idlib province), Lebanon, Africa (Kenya, Libya), and France (northern France), amongst others, have been gathered into crowded refugee camps and makeshift settlements, and threatened by the coronavirus spread (UNHCR, 2020).

In Bangladesh, refugee volunteers and aid workers have been struggling to educate people in these camps about the coronavirus to limit the spread of the virus (UNHCR, 2020). In Syria, families have been moved from large communal tents to individual tents, but social distancing is almost impossible (UNHCR, 2020). In Kenya, the United Nations High Commissioner for Refugees (UNHCR) has reduced contacts between residents and humanitarian workers (UNHCR, 2020). In addition to closing schools, some businesses and markets, and imposing curfews, UNHCR has been urging governments to include refugees and asylum-seekers in national plans to combat COVID-19 in Libya (UNHCR, 2020). In France, French authorities transferred up to 2,100 refugees and migrants in Calais and Dunkirk from 
informal camps to accommodation centers where they would be expected to follow the same coronavirus lockdown rules as the rest of France (UNHCR, 2020). In Lebanon, many steps have been taken to distribute soap, set-up isolation units and support Lebanon's health system to set up more intensive care units (UNHCR, 2020).

Refugees, asylum seekers, and displaced persons having fled the horrors of war, terrorism, and persecution, want to rebuild their lives, and become a part of their new community. They have to face difficult living conditions, economic hardship, discrimination, social exclusion, and exploitation and, as mentioned before, are often exposed to severe mental and physical strain due to war, violence, political and religious persecution, poverty, imprisonment, or torture (Xin et al., 2017). Forced migration and resettlement are associated with distressing circumstances that contribute to poor physical and psychological wellbeing including high rates of trauma and other stress-related disorders (Ley et al., 2018; Ley and Barrio, 2019). Also, physical inactivity is a common phenomenon among refugees and immigrant populations (Crespo, 2000; Gerber et al., 2012). Refugee/asylum seeker status may affect the decision to engage with $\mathrm{PA}$ and/or exercise due to competing priorities, the temporary nature of living and mental and physical health (Haith-Cooper et al., 2018).

\section{COVID-19 OUTBREAK'S IMPACT ON PRISONERS}

The COVID-19 outbreak can occur easily in environments such as the jail and prison that represent shared or congregate living environments, due to the higher number of people working or residing in correctional facilities. Jails and prisons are constructed to maximize public safety to prevent the transmission of disease or to efficiently deliver health care. However, jails and prisons often lack sufficient hand washing areas, isolation rooms, and personal protective equipment (Bick, 2007) that may increase the probability of transmission of the virus amid inmates. Visits to prisons are temporarily suspended in many countries worldwide (Hewson et al., 2020) and the loss of such visits could lessen the use of social support for mitigating against and coping with mental distress and the risk of suicide and self-harm among prisoners (De Claire and Dixon, 2017).

As the virus continues to spread, the public health response to the pandemic in correctional facilities becomes more and more challenging and warrants a holistic approach. Attempts to control the COVID-19 community transmission are not likely to succeed if strict infection prevention and control measures, including testing, treatment, and care, are not implemented in prisons and other places of detention as well. As part of the response, the WHO has worked with relevant institutions and stakeholders to develop guidelines on preparedness, prevention, and management of COVID-19 in prisons as well as in other places of detention.

In addition, correctional facilities should provide sanitary guidelines to inmates who are exposed to air-borne droplets during staying in their cells or family visiting. Inmates, who tested positives and have the risk to transmit the virus through culinary activities in prison, should obviously be isolated and medically controlled and be careful regarding how to store, prepare and eat perishable food in their cells (CDC, 2020).

Staying home is not an option for people who are in prisons and jails across the world and social distancing is nearly impossible to practice except in solitary confinement. This results in dramatically impacting mental and physical health (Reiter et al., 2020). According to Human rights agencies, long-term solitary confinement is a torture (Reiter et al., 2020) and refers to the physical and social isolation of an individual which can induce psychological harms of segregation including self-harm, anxiety, depression, paranoia, and aggression (Kaba et al., 2014; Haney, 2018). Isolated prisoners would typically spend their time in a single cell for 22.5-24 h a day and solitary confinement can last for months or years, and can be of an indeterminate duration which can promote a sense of helplessness and increase hostility and aggression (Shalev, 2008).

Incarcerated inmates in jail facilities have an increased risk of human immunodeficiency virus infection, hepatitis $\mathrm{B}$ virus infection, hepatitis $\mathrm{C}$ virus infection, syphilis, gonorrhea, chlamydia, and Mycobacterium tuberculosis infection (Hammett et al., 2002), the acquisition of infection with airborne organisms, such as $M$. tuberculosis, influenza virus, and varicella-zoster virus (Bick, 2007), as well as high rates of hypertension (Binswanger et al., 2009; Trotter et al., 2018), poor sleep quality (Harner and Budescu, 2014), anxiety, and depression (Binswanger et al., 2010).

Practicing social distance in prisons is difficult due to the issues of overcrowding and the fear increases if correctional facilities become epicenters in the coronavirus pandemic. Correctional facilities try to minimize the risk of transmission by quarantining a sick prisoner which is the segregation that is usually used as a punitive measure. Another way to protect inmates who are elderly, immunocompromised, medically vulnerable, close to release, or associated with minor, nonviolent crimes, is to decarcerate or release them. Indeed, sending them home can protect prisoners, correctional workers, their families and the broader community. Upon release from prison, many individuals experience difficulty in maintaining good health (Wallace and Wang, 2020) because infected prisoners might bring disease from jail into their communities. Therefore, in case of pandemic, released prisoners should pass by a quarantine period before entering in contact with their family members and community.

Imprisoned people have usually a poor health status in comparison with the general population (Fazel and Baillargeon, 2011; Mannocci et al., 2015). More than 40 of the 50 largest clustered outbreaks in the United States have occurred in jails and prisons (Macmadu et al., 2020) and the number of COVID19 cases is 5.5 times higher among people who are incarcerated (Saloner et al., 2020). Several behavioral factors including use of intravenous drug, alcohol misuse, smoking, and physical inactivity could increase the risk of morbidity, mortality, and mental disorders (Brinded et al., 2001; Cashin et al., 2008; Fischer et al., 2012; Battaglia et al., 2015). As well, overcrowding, and 
high occupant turnover may increase the risks of transmission in prisons and jails (Macmadu et al., 2020).

\section{PA/EXERCISE DURING COVID-19 PANDEMIC}

As of today, clinical practice, community programs, mass-media campaigns, and population strategies have focused mainly on encouraging and supporting individuals to be more active, during staying at home. As the mortality rate of patients with positive COVID-19 test and confined and isolated people continues to increase and chronic medical problems from inactivity become increasingly prevalent, there is now an imperative to increase the PA levels of refugees, asylum seekers, and prisoners and overall total daily energy expenditure.

During the COVID-19 induced confinement, the behavior of prolonged sitting time that is a predictor of weight gain, requires that individuals should be aware of the amount of PA necessary to achieve better health outcomes, understand the importance of PA and exercise in relation to good physical and mental health, and prevent overweight, obesity and chronic disease (Owen et al., 2009). PA is defined as any bodily movement produced by skeletal muscles which results in energy expenditure and can be categorized into occupational, sports, conditioning, household, or other activities. Exercise is a planned and structured program of motor actions to improve or maintain components of physical fitness (Caspersen et al., 1985). As previously mentioned, PA/Exercise is a potent stimulus of immune function (Ghram et al., 2020a; Laddu et al., 2020) to fight against the mental and physical consequences of COVID-19 quarantine (Jiménez-Pavón et al., 2020). The types of exercise prescribed can vary by mode, dose, setting, the person who delivers the intervention, and any accompanying behavioral strategies (e.g. counseling, pamphlets) (Campbell et al., 2007). To attenuate negative effects of SB and physical inactivity, individuals are required to participate in regular PA and minimize the time they spend sitting to prevent cardiovascular and metabolic disease, certain types of cancer, and mental deficits (Vogel et al., 2009; Piercy et al., 2018).

Social and physical distancing and isolation are required to stop the transmission of infectious disease. Facing this new situation, exercise professionals encourage people to maintain good health and have recommended to use online technology to prescribe, and monitor exercise, such as mobile telephones messages, apps, email, video calls, or other internet-based strategies (de Oliveira Neto et al., 2020; Ghram et al., 2020a). Isolated/confined or imprisoned individuals should raise energy expenditure as much as is necessary by participating in moderate to vigorous PA to prevent obesity and decrease sedentary time. While the benefits of PA are not disputed, reducing sedentary time is of vital importance (Bowden Davies et al., 2019).

Physical exercise can be a major part of a multi-component strategy targeted at reducing psychological ill health in asylum seekers, refugees, and prisoners (Mannocci et al., 2017). Evidence shows that physical exercise is widely recommended for general and specific populations to maintain health status, improve daily life activities, play a fundamental role in protecting against disease, and provide biological and psychological benefits. The American College of Sports Medicine (ACSM) has released information on how to remain active during the COVID19 pandemic (ACSM, 2020) and has emphasized the positive effects of the regular practice of physical exercise on the enhancement of the immunological system in humans, showing that physically active people have a lower risk of developing chronic-degenerative diseases, which is highly pertinent and related to COVID-19, as those affected are at higher risk if infected by SARS-CoV-2 (Pedersen and Saltin, 2015; de Oliveira Neto et al., 2020). Therefore, people in isolation and with a positive diagnosis for COVID-19, but who are asymptomatic, should be able to continue the regular practice of moderate intensity PA. However, in the presence of symptoms (e.g., fever, cough, and dyspnea), the practice of PA should be interrupted and medical assistance should be sought (Joy, 2020). Special attention should be paid to asylum seekers, refugees, and prisoners, because among these vulnerable populations PA and exercise have benefits on physical and mental health and can prevent psychological disorders.

\section{PA/EXERCISE AS AN EFFECTIVE COUNTERMEASURE TO THE PSYCHO-SOCIAL EFFECTS OF COVID-19 AMONG REFUGEES AND ASYLUM SEEKERS}

Considering that asylum seekers and refugees represent highly heterogeneous groups with different cultural backgrounds and might be more prone to the psychosocial impact of the COVID-19 pandemic, PA/exercise might be an effective and safe alternative to mitigate this risk and reduce the breadth and depth of physical and mental needs of these vulnerable groups.

Among immigrants and those seeking refuge into highly developed nations, PA level is not satisfactory and, in general, lower than among non-immigrants (Sternfeld et al., 1999; Crespo et al., 2000; Gadd et al., 2005), and programs aimed at increasing PA within 10 years of arrival may be particularly effective (Goel et al., 2004). Exercises and sports-related activities can be utilized to properly treat various psychiatric diseases (Lam and Riba, 2016), and are instrumental to human wellbeing (Lederman et al., 2017). Even though international organisms, such as the UNHCR, acknowledge the feasibility of exploiting exercise and sport as a peace-building measure in refugee camps with healthy individuals (Korsik et al., 2013), evidence has shown that adequate PA levels have also a beneficial impact on traumatized subjects (Rosenbaum et al., 2015, 2018).

Twelve weeks of biofeedback-based cognitive behavioral therapy (CBT-BF) combined with PA (including mixed activities such as flexibility, strength, and endurance training) resulted in enhanced coping strategies and mechanisms to face pain with respect to CBT-BF alone or a waiting-list control condition in 36 refugees from Germany and Switzerland reporting PTSD symptoms (Liedl et al., 2011). In another study from Denmark, Stade et al. (2015) reported high acceptability, compliance and 
satisfaction with basic body awareness therapy (BBAT). Positive effects on mental health outcomes were observed after 12 weeks of regular physical activity among Bosnian refugees in the United States (Xin et al., 2017). Regularly attending a 8-week sport and exercise program has been found to exert a positive influence on a wide range of mental health outcomes, including PTSD, depressive, anxiety symptoms, health-related quality of life, handgrip strength, and perceived and cardiorespiratory fitness (Knappe et al., 2019).

Moderate PA and/or sport can beneficially modulate physical and mental health and wellbeing for refugees and asylum seekers living in particularly challenging conditions. Refugees and asylum seekers should be instructed about accumulating adequate PA levels through changes in their lifestyle [for example, by walking faster or increasing intensity when carrying out housework (Haith-Cooper et al., 2018)]. Thus, performing PA during the COVID-19 pandemic could potentially help these populations better cope with their limited movement and difficult psychological conditions.

\section{PA/EXERCISE AS AN EFFECTIVE COUNTERMEASURE TO THE PSYCHO-SOCIAL EFFECTS OF COVID-19 AMONG PRISONERS}

Prisoners and inmates are at higher risk of adopting unhealthy lifestyles such as tobacco smoking, drug abuse, low physical activity and irregular dietary habits, factors that may lead to the insurgence of acute and chronic physical and psychological disorders (Mannocci et al., 2015).

Lack of PA may affect negatively psychological status of prisoners and inmates and increase anxiety (Boothby and Clements, 2000), stress, and depression (Plugge and Fitzpatrick, 2005) rates. One of the factors challenging their ability to practice PA and exercise is overcrowding (WHO Regional Office for Europe, 2020). Thus, prisoners experience difficulties in moving and undertaking the necessary amount of moderate PA necessary to benefit their health (WHO Regional Office for Europe, 2020). A "decent" prison regime should ensure that prisoners are able to be compliant with the WHO guidelines and recommendations on PA, and are sufficiently instructed how to make an informed choice about optimal PA and exercise programs and strategies (WHO Regional Office for Europe, 2020). It was shown that PA is a simple and cost-effective way to positively modulate the health-related quality of life (QoL) of prisoners and can contribute to achieving "healthy prison" objectives in practice (Meek and Lewis, 2012). Regular physical exercise can enhance inmates QoL, allow a better social cohesion and integration at the end of detention in prisons (Mannocci et al., 2015), reduce depression, anxiety, stress (Buckaloo et al., 2009), and sleep problems such as insomnia (Elger, 2009), increase muscle tone, strength, stamina (Nelson et al., 2006), and functional capacity (Battaglia et al., 2013), and improve overall physical fitness of incarcerated people (Pérez-Moreno et al., 2007).
Taking into consideration the health status of prisoners, the lack of availability of safe equipment for training, and the limited space derived from the condition of being incarcerated, we suggest to make a bodyweight workout plan to help the prisoner get ripped while being in isolation. Warm-up should last at least $10 \mathrm{~min}$ (jog on the spot, high knee tucks, butt kicks, skip, forward lunge and twist, carioca, lateral lunge and twist, slides, high knee crossovers, exaggerated backpedal). Other exercises can be performed easily such as Push-Up, Dips, Sit-Ups, Squats, Burpees, Star-Jumps, Wide-Grip Pull-Ups, and Step-Ups. Furthermore, relaxation techniques and stretching exercises are easy to carry out in a practical fashion without the risk of being exposed to a contaminated environment and are effective in promoting health gains and reduce stress levels (Bentlage et al., 2020; Ghram et al., 2020a). Stretching exercises may improve stability and balance of these vulnerable populations (Costa et al., 2009; Handrakis et al., 2010; Ryan et al., 2010; Chatzopoulos et al., 2014; Ghram et al., 2016, 2020b).

\section{PRACTICAL RECOMMENDATIONS}

Coronavirus Disease 2019 outbreak poses significant challenges to these specific populations. Preventative healthcare measures should be implemented to reduce disease transmissions within prisons and camps and decrease negative mental health problems wherever possible. Since less attention for these specific populations compared to the general population is generally paid, we recommend that these vulnerable populations are potentially encouraged to stay more physically active, and informed about the risk of SB and physical inactivity. There is increasing need in this community to encourage prisoners, asylum seekers, and refugees to engage at least in low exercise intensity to enhance their fitness, physical and psychological health, and wellbeing and reduce the risk of disability. In further research, researchers and scientists are required to focus on developing more efficient strategies to reduce the negative effect of pandemic spread. Future studies should investigate the impact of PA and exercise in these vulnerable groups during pandemic outbreak, as well as after having achieved the full control of the spread of the epidemic in non-infected and infected individuals.

\section{CONCLUSION}

The COVID-19 pandemic is still ongoing, exerting a dramatic, detrimental impact on PA-related patterns and sedentary lifestyle and posing severe challenges for asylum seekers, refugees, and prisoners, globally. The available body of evidence suggests that exercise is medicine and protects from infections, mainly among specific vulnerable and frail populations. Physical exercise, indeed, positively impacts mental wellbeing and provides protection to individuals against depression and anxiety as it causes biochemical and biophysical changes in the brain which can positively influence their mood. Since public health measures (confinement, isolation, social and physical distancing) are aimed to protect vulnerable populations during pandemic, 
but, on a long-term scale, may have secondary negative effects on health and well-being, these specific vulnerable populations should live in adequate physical conditions, having regular access to fresh, healthy air and being able to practice PA/exercise. Notwithstanding variations in individual tolerance to living in confined environments, there is remarkable evidence of the consistency of public health measures psychological as well as physiological health effects. In addition, PA/exercise can be considered as a viable tool for the treatment, and

\section{REFERENCES}

ACSM (2020). Staying Active During the Coronavirus Pandemic 2020. Available online at: https://www.exerciseismedicine.org/assets/page_documents/EIM_ Rx\%20for\%20Health_\%20Staying\%20Active\%20During\%20Coronavirus\% 20Pandemic.pdf (accessed 24 April, 2021).

Ainsworth, B. E., and Li, F. (2020). Physical activity during the coronavirus disease2019 global pandemic. J. Sport Health Sci. 9, 291-292. doi: 10.1016/j.jshs.2020. 06.004

Ammar, A., Chtourou, H., Boukhris, O., Trabelsi, K., Masmoudi, L., Brach, M., et al. (2020a). COVID-19 home confinement negatively impacts social participation and life satisfaction: a worldwide multicenter study. Int. J. Environ. Res. Publ. Health 17:6237.

Ammar, A., Mueller, P., Trabelsi, K., Chtourou, H., Boukhris, O., Masmoudi, L., et al. (2020b). Psychological consequences of COVID-19 home confinement: the ECLB-COVID19 multicenter study. PLoS One 15:e0240204. doi: 10.1371/ journal.pone.0240204

Ammar, A., Trabelsi, K., Brach, M., Chtourou, H., Boukhris, O., Masmoudi, L., et al. (2021). Effects of home confinement on mental health and lifestyle behaviours during the COVID-19 outbreak: insight from the ECLBCOVID19 multicenter study. Biol. Sport 38, 9-21. doi: 10.5114/biolsport.2020. 96857

Bao, R., Chen, S. T., Wang, Y., Xu, J., Wang, L., Zou, L., et al. (2020). Sedentary behavior research in the Chinese population: a systematic scoping review. Int. J. Environ. Res. Publ. Health 17:3576. doi: 10.3390/ijerph171 03576

Battaglia, C., di Cagno, A., Fiorilli, G., Giombini, A., Borrione, P., Baralla, F., et al. (2015). Participation in a 9-month selected physical exercise programme enhances psychological well-being in a prison population. Crim. Behav. Ment. Health 25, 343-354. doi: 10.1002/cbm.1922

Battaglia, C., di Cagno, A., Fiorilli, G., Giombini, A., Fagnani, F., Borrione, P., et al. (2013). Benefits of selected physical exercise programs in detention: a randomized controlled study. Int. J. Environ. Res. Publ. Health 10, 5683-5696. doi: 10.3390/ijerph10115683

Bell, D., Nicoll, A., Fukuda, K., Horby, P., Monto, A., Hayden, F., et al. (2006). Nonpharmaceutical interventions for pandemic influenza, national and community measures. Emerg. Infect. Dis. 12, 88-94. doi: 10.3201/eid1201.051371

Bentlage, E., Ammar, A., How, D., Ahmed, M., Trabelsi, K., Chtourou, H., et al. (2020). Practical recommendations for maintaining active lifestyle during the COVID-19 pandemic: a systematic literature review. Int. J. Environ. Res. Publ. Health 17:6265. doi: 10.3390/ijerph17176265

Bick, J. A. (2007). Infection control in jails and prisons. Clin. Infect. Dis. 45, 1047-1055. doi: 10.1086/521910

Binswanger, I. A., Krueger, P. M., and Steiner, J. F. (2009). Prevalence of chronic medical conditions among jail and prison inmates in the USA compared with the general population. J. Epidemiol. Commun. Health 63, 912-919. doi: 10. 1136/jech.2009.090662

Binswanger, I. A., Merrill, J. O., Krueger, P. M., White, M. C., Booth, R. E., and Elmore, J. G. (2010). Gender differences in chronic medical, psychiatric, and substance-dependence disorders among jail inmates. Am. J. Publ. Health 100, 476-482. doi: 10.2105/AJPH.2008.149591

Bok, D., Chamari, K., and Foster, C. (2020). The pitch invader: COVID-19 cancelled the game:-what can science do for us, and what can the pandemic do for science? Int. J. Physiol. Perform. doi: 10.1123/ijspp.2020-0467 [Epub ahead of print]. management of people who are living in confined environments and/or are experiencing limited movement because of virusrelated outbreaks.

\section{AUTHOR CONTRIBUTIONS}

AG, NLB, and KC conceived the manuscript. All authors wrote and revised the manuscript.

Boothby, J. L., and Clements, C. B. (2000). A national survey of correctional psychologists. Crim. Just. Behav. 27, 716-732. doi: 10.1177/0093854800027006003

Bowden Davies, K. A., Pickles, S., Sprung, V. S., Kemp, G. J., Alam, U., Moore, D. R., et al. (2019). Reduced physical activity in young and older adults: metabolic and musculoskeletal implications. Therap. Adv. Endocrinol. Metab. 10, 2042018819888824. doi: 10.1177/2042018819888824

Brinded, P. M., Simpson, A. I., Laidlaw, T. M., Fairley, N., and Malcolm, F. (2001). Prevalence of psychiatric disorders in New Zealand prisons: a national study. Austr. N. Zeal. J. Psychiatry. 35, 166-173. doi: 10.1046/j.1440-1614.2001.00885. $\mathrm{x}$

Buckaloo, B. J., Krug, K. S., and Nelson, K. B. (2009). Exercise and the lowsecurity inmate:changes in depression. Stress Anxiety Prison J. 89, 328-343. doi: 10.1177/0032885509339508

Burke, R. M., Midgley, C. M., Dratch, A., Fenstersheib, M., Haupt, T., Holshue, M., et al. (2020). Active monitoring of persons exposed to patients with confirmed COVID-19 - United States, January-February 2020. MMWR Morb. Mortal. Week. Rep. 69, 245-246. doi: 10.15585/mmwr.mm6909e1

Campbell, N. C., Murray, E., Darbyshire, J., Emery, J., Farmer, A., Griffiths, F., et al. (2007). Designing and evaluating complex interventions to improve health care. BMJ 334, 455-459. doi: 10.1136/bmj.39108.379965.BE

Cao, W., Kim, J. H., Chirkova, T., Reber, A. J., Biber, R., Shay, D. K., et al. (2011). Improving immunogenicity and effectiveness of influenza vaccine in older adults. Expert Rev. Vacc. 10, 1529-1537. doi: 10.1586/erv.11.137

Cashin, A., Potter, E., and Butler, T. (2008). The relationship between exercise and hopelessness in prison. J. Psychiatr. Ment. Health Nurs. 15, 66-71. doi: 10.1111/j.1365-2850.2007.01207.x

Caspersen, C. J., Powell, K. E., and Christenson, G. M. (1985). Physical activity, exercise, and physical fitness: definitions and distinctions for health-related research. Publ. Health Rep. 100, 126-131.

CDC (2020). Interim Guidance on Management of Coronavirus Disease 2019 (COVID-19) in Correctional and Detention Facilities 2020. Atlanta: CDC.

Chan, J. F., Yuan, S., Kok, K. H., To, K. K., Chu, H., Yang, J., et al. (2020). A familial cluster of pneumonia associated with the 2019 novel coronavirus indicating person-to-person transmission: a study of a family cluster. Lancet 395, 514-523. doi: 10.1016/S0140-6736(20)30154-9

Chatzopoulos, D., Galazoulas, C., Patikas, D., and Kotzamanidis, C. (2014). Acute effects of static and dynamic stretching on balance, agility, reaction time and movement time. J. Sports Sci. Med. 13, 403-409.

Chtourou, H., Trabelsi, K., H'mida, C., Boukhris, O., Glenn, J. M., Brach, M., et al. (2020). Staying physically active during the quarantine and self-isolation period for controlling and mitigating the COVID-19 pandemic: a systematic overview of the literature. Front. Psychol. 11:1708. doi: 10.3389/fpsyg.2020.01708

Costa, P. B., Graves, B. S., Whitehurst, M., and Jacobs, P. L. (2009). The acute effects of different durations of static stretching on dynamic balance performance. J. Strength Cond. Res. 23, 141-147. doi: 10.1519/JSC.0b013e31818eb052

Crespo, C. J. (2000). Encouraging physical activity in minorities: eliminating disparities by 2010. Phys. Sports Med. 28, 36-51. doi: 10.3810/psm.2000.10.1230

Crespo, C. J., Smit, E., Andersen, R. E., Carter-Pokras, O., and Ainsworth, B. E. (2000). Race/ethnicity, social class and their relation to physical inactivity during leisure time: results from the Third National Health and Nutrition Examination Survey, 1988-1994. Am. J. Prev. Med. 18, 46-53. doi: 10.1016/ S0749-3797(99)00105-1

De Claire, K., and Dixon, L. (2017). The effects of prison visits from family members on prisoners' well-being, prison rule breaking, and recidivism: a 
review of research since 1991. Trauma Viol. Abuse 18, 185-199. doi: 10.1177/ 1524838015603209

de Oliveira Neto, L., de Oliveira Tavares, V. D., Schuch, F. B., and Lima, K. C. (2020). Coronavirus pandemic (SARS-COV-2): pre-exercise screening questionnaire (PESQ) for telepresential exercise. Front. Public Health 8:146. doi: 10.3389/fpubh.2020.00146

Dunstan, D. W., Barr, E. L. M., Healy, G. N., Salmon, J., Shaw, J. E., Balkau, B., et al. (2010). Television viewing time and mortality. Circulation 121, 384-391. doi: 10.1161/CIRCULATIONAHA.109.894824

ECDC (2020). Coronavirus Disease 2019 (COVID-19) Pandemic: Increased Transmission in the EU/EEA and the UK 2020. Available online at: https://www.ecdc.europa.eu/sites/default/files/documents/RRA-seventhupdate-Outbreak-of-coronavirus-disease-COVID-19.pdf (accessed 24 April, 2021).

Elger, B. S. (2009). Prison life: television, sports, work, stress and insomnia in a remand prison. Int. J. Law Psychiatry 32, 74-83. doi: 10.1016/j.ijlp.2009.01.001

Fazel, S., and Baillargeon, J. (2011). The health of prisoners. Lancet 377, 956-965. doi: 10.1016/S0140-6736(10)61053-7

Fehr, A. R., and Perlman, S. (2015). Coronaviruses: an overview of their replication and pathogenesis. Methods Mol. Biol. 1282, 1-23. doi: 10.1007/978-1-49392438-7_1

Fischer, J., Butt, C., Dawes, H., Foster, C., Neale, J., Plugge, E., et al. (2012). Fitness levels and physical activity among class A drug users entering prison. Br. J. Sports Med. 46, 1142-1144. doi: 10.1136/bjsports-2011-09 0724

Gadd, M., Sundquist, J., Johansson, S.-E., and Wändell, P. (2005). Do immigrants have an increased prevalence of unhealthy behaviours and risk factors for coronary heart disease? Eur. J. Cardiovasc. Prevent. Rehabil. 12, 535-541. doi: 10.1097/01.hjr.0000174829.25388.ed

Gerber, M., Barker, D., and Pühse, U. (2012). Acculturation and physical activity among immigrants: a systematic review. J. Publ. Health 20, 313-341. doi: 10.1007/s10389-011-0443-1

Gerritsen, A. A. M., Bramsen, I., Devillé, W., van Willigen, L. H. M., Hovens, J. E., and van der Ploeg, H. M. (2006). Physical and mental health of Afghan, Iranian and Somali asylum seekers and refugees living in the Netherlands. Soc. Psychiatry Psychiatr. Epidemiol. 41, 18-26. doi: 10.1007/s00127-0050003-5

Ghram, A., Briki, W., Mansoor, H., Al-Mohannadi, A. S., Lavie, C. J., and Chamari, K. (2020a). Home-based exercise can be beneficial for counteracting sedentary behavior and physical inactivity during the COVID-19 pandemic in older adults. Postgrad. Med. doi: 10.1080/00325481.2020.1860394 [Epub ahead of print].

Ghram, A., Damak, M., Rhibi, F., and Marchetti, P. H. (2016). The ContractRelax Proprioceptive Neuromuscular Facilitation (PNF) Stretching Can Affect the Dynamic Balance in Healthy Men. São Paulo: MedicalExpress, 3. doi: 10.5935/ MedicalExpress.2016.04.04

Ghram, A., Yahia, A., Damak, M., Safaei Motlagh, A., Jribi, S., and Costa, P. B. (2020b). Effects of different types of proprioceptive neuromuscular facilitation stretching on dynamic balance control. Sport Sci. Health 16, 451-458. doi: 10.1007/s11332-020-00623-9

Gilani, S., Roditi, R., and Naraghi, M. (2020). COVID-19 and anosmia in Tehran, Iran. Med. Hypothes. 141:109757. doi: 10.1016/j.mehy.2020.109757

Goel, M. S., McCarthy, E. P., Phillips, R. S., and Wee, C. C. (2004). Obesity among US immigrant subgroups by duration of residence. JAMA 292, 2860-2867. doi: 10.1001/jama.292.23.2860

Haith-Cooper, M., Waskett, C., Montague, J., and Horne, M. (2018). Exercise and physical activity in asylum seekers in Northern England; using the theoretical domains framework to identify barriers and facilitators. BMC Publ. Health 18:762. doi: 10.1186/s12889-018-5692-2

Hammett, T. M., Harmon, M. P., and Rhodes, W. (2002). The burden of infectious disease among inmates of and releasees from US correctional facilities, 1997. Am. J. Publ. Health 92, 1789-1794. doi: 10.2105/AJPH.92.11.1789

Handrakis, J. P., Southard, V. N., Abreu, J. M., Aloisa, M., Doyen, M. R., Echevarria, L. M., et al. (2010). Static stretching does not impair performance in active middle-aged adults. J. Strength Cond. Res. 24, 825-830. doi: 10.1519/JSC. 0b013e3181ad4f 89

Haney, C. (2018). The psychological effects of solitary confinement: a systematic critique. Crime Just. 47, 365-416. doi: 10.1086/696041
Harner, H. M., and Budescu, M. (2014). Sleep quality and risk for sleep apnea in incarcerated women. Nurs. Res. 63, 158-169. doi: 10.1097/NNR. 0000000000000031

Hewson, T., Shepherd, A., Hard, J., and Shaw, J. (2020). Effects of the COVID19 pandemic on the mental health of prisoners. Lancet Psychiatry 7, 568-570. doi: 10.1016/S2215-0366(20)30241-8

Holshue, M. L., DeBolt, C., Lindquist, S., Lofy, K. H., Wiesman, J., Bruce, H., et al. (2020). First case of 2019 novel coronavirus in the United States. N. Engl. J. Med. 382, 929-936. doi: 10.1056/NEJMoa2001191

Huang, C., Wang, Y., Li, X., Ren, L., Zhao, J., Hu, Y., et al. (2020). Clinical features of patients infected with 2019 novel coronavirus in Wuhan, China. Lancet 395, 497-506. doi: 10.1016/S0140-6736(20)30183-5

Jiménez-Pavón, D., Carbonell-Baeza, A., and Lavie, C. J. (2020). Physical exercise as therapy to fight against the mental and physical consequences of COVID-19 quarantine: special focus in older people. Prog. Cardiovasc. Dis. 63, 386-388. doi: 10.1016/j.pcad.2020.03.009

Joy, L. (2020). Staying Active During COVID-19 2020. Available online at: https: //www.exerciseismedicine.org/support_page.php/stories/?b=892 (accessed 24 April, 2021).

Kaba, F., Lewis, A., Glowa-Kollisch, S., Hadler, J., Lee, D., Alper, H., et al. (2014). Solitary confinement and risk of self-harm among jail inmates. Am. J. Publ. Health 104, 442-447. doi: 10.2105/AJPH.2013.301742

Kain, T., and Fowler, R. (2019). Preparing intensive care for the next pandemic influenza. Crit. Care 23:337. doi: 10.1186/s13054-019-2616-1

Katzmarzyk, P. T., Church, T. S., Craig, C. L., and Bouchard, C. (2009). Sitting time and mortality from all causes, cardiovascular disease, and cancer. Med. Sci. Sports Exerc. 41, 998-1005. doi: 10.1249/MSS.0b013e31819 30355

Khan, S., Siddique, R., Li, H., Ali, A., Shereen, M. A., Bashir, N., et al. (2020). Impact of coronavirus outbreak on psychological health. J. Glob. Health 10:010331. doi: 10.7189/jogh.10.010331

Knappe, F., Colledge, F., and Gerber, M. (2019). Impact of an 8-week exercise and sport intervention on post-traumatic stress disorder symptoms, mental health, and physical fitness among male refugees living in a Greek refugee camp. Int. J. Environ. Res. Publ. Health 16:3904. doi: 10.3390/ijerph16203904

Kohut, M. L., Arntson, B. A., Lee, W., Rozeboom, K., Yoon, K.-J., Cunnick, J. E., et al. (2004). Moderate exercise improves antibody response to influenza immunization in older adults. Vaccine 22, 2298-2306. doi: 10.1016/j.vaccine. 2003.11.023

Korsik, A., Ivarsson, V., Nakitanda, O. A., and Perez Rosas, L. (2013). Implementing Sports in Refugee Camps. Lausanne: AISTS.

Laddu, D. R., Lavie, C. J., Phillips, S. A., and Arena, R. (2020). Physical activity for immunity protection: inoculating populations with healthy living medicine in preparation for the next pandemic. Prog. Cardiovasc. Dis. 64, 102-104. doi: 10.1016/j.pcad.2020.04.006

Lam, L. C., and Riba, M. (2016). Physical Exercise Interventions for Mental Health. Cambridge: Cambridge University Press. doi: 10.1017/CBO9781316157565

Lederman, O., Suetani, S., Stanton, R., Chapman, J., Korman, N., Rosenbaum, S., et al. (2017). Embedding exercise interventions as routine mental health care: implementation strategies in residential, inpatient and community settings. Aust. Psychiatry 25, 451-455. doi: 10.1177/1039856217711054

Ley, C., and Barrio, M. R. (2019). Promoting Health of Refugees in and Through Sport and Physical Activity: A Psychosocial, Trauma-Sensitive Approach. An Uncertain Safety. Berlin: Springer, 301-343. doi: 10.1007/978-3-319-729 14-5_13

Ley, C., Rato Barrio, M., and Koch, A. (2018). "In the sport I am here": therapeutic processes and health effects of sport and exercise on PTSD. Qual. Health Res. 28, 491-507. doi: 10.1177/1049732317744533

Li, Q., Guan, X., Wu, P., Wang, X., Zhou, L., Tong, Y., et al. (2020). Early transmission dynamics in Wuhan, China, of novel coronavirus-infected pneumonia. N. Engl. J. Med. 382, 1199-1207. doi: 10.1056/NEJMoa2001316

Li, S., Wang, Y., Xue, J., Zhao, N., and Zhu, T. (2020). The impact of COVID-19 epidemic declaration on psychological consequences: a study on active weibo users. Int. J. Environ. Res. Publ. Health 17:2032. doi: 10.3390/ijerph17062032x

Liedl, A., Müller, J., Morina, N., Karl, A., Denke, C., and Knaevelsrud, C. (2011) Retracted: physical activity within a CBT intervention improves coping with pain in traumatized refugees: results of a randomized controlled design. Pain Med. 12, 234-245. doi: 10.1111/j.1526-4637.2010.01040.x 
Liu, J., Liao, X., Qian, S., Yuan, J., Wang, F., Liu, Y., et al. (2020). Community transmission of severe acute respiratory syndrome coronavirus 2, Shenzhen, China, 2020. Emerg. Infect. Dis. 26, 1320-1323. doi: 10.3201/eid2606.200239

Macmadu, A., Berk, J., Kaplowitz, E., Mercedes, M., Rich, J. D., and BrinkleyRubinstein, L. (2020). COVID-19 and mass incarceration: a call for urgent action. Lancet Publ. Health 5, e571-e572. doi: 10.1016/S2468-2667(20)30231-0

Mannocci, A., Masala, D., Mipatrini, D., Rizzo, J., Meggiolaro, S., Di Thiene, D., et al. (2015). The relationship between physical activity and quality of life in prisoners: a pilot study. J. Prev. Med. Hyg. 56, E172-E175.

Mannocci, A., Mipatrini, D., D’Egidio, V., Rizzo, J., Meggiolaro, S., Firenze, A., et al. (2017). Health related quality of life and physical activity in prison: a multicenter observational study in Italy. Eur. J. Publ. Health 28, 570-576. doi: 10.1093/eurpub/ckx183

Martin, A., Markhvida, M., Hallegatte, S., and Walsh, B. (2020). Socioeconomic impacts of COVID-19 on household consumption and poverty. Econ. Disast. Clim. Change 4, 453-479. doi: 10.1007/s41885-020-00 070-3

Meek, R., and Lewis, G. (2012). The role of sport in promoting prisoner health. Int. J. Prison. Health 8, 117-130. doi: 10.1108/17449201211284996

Nelson, M., Specian, V. L., Tracy, N. C., and DeMello, J. J. (2006). The effects of moderate physical activity on offenders in a rehabilitative program. J. Correct. Educ. 57, 276-285.

Ong, S. W. X., Tan, Y. K., Chia, P. Y., Lee, T. H., Ng, O. T., Wong, M. S. Y., et al. (2020). Air, surface environmental, and personal protective equipment contamination by severe acute respiratory syndrome coronavirus 2 (SARSCoV-2) from a symptomatic patient. JAMA 323, 1610-1612. doi: 10.1001/jama. 2020.3227

Otu, A., Ebenso, B., Labonte, R., and Yaya, S. (2020). Tackling COVID-19: can the African continent play the long game? J. Glob. Health 10:010339. doi: 10.7189/jogh.10.010339

Owen, N., Bauman, A., and Brown, W. (2009). Too much sitting: a novel and important predictor of chronic disease risk? Br. J. Sports Med. 43, 81-83. doi: 10.1136/bjsm.2008.055269

Pedersen, B. K., and Saltin, B. (2015). Exercise as medicine - evidence for prescribing exercise as therapy in 26 different chronic diseases. Scand. J. Med. Sci. Sports 25(Suppl. 3), 1-72. doi: 10.1111/sms.12581

Pérez-Moreno, F., Cámara-Sánchez, M., Tremblay, J. F., Riera-Rubio, V. J., GilPaisán, L., and Lucia, A. (2007). Benefits of exercise training in Spanish prison inmates. Int. J. Sports Med. 28, 1046-1052. doi: 10.1055/s-2007-96 5129

Piercy, K. L., Troiano, R. P., Ballard, R. M., Carlson, S. A., Fulton, J. E., Galuska, D. A., et al. (2018). The physical activity guidelines for Americans. JAMA 320, 2020-2028. doi: 10.1001/jama.2018.14854

Plugge, E., and Fitzpatrick, R. (2005). Assessing the health of women in prison: a study from the United Kingdom. Health Care Women Int. 26, 62-68. doi: $10.1080 / 07399330590885768$

Ramalingam, S., Graham, C., Dove, J., Morrice, L., and Sheikh, A. (2020). Hypertonic saline nasal irrigation and gargling should be considered as a treatment option for COVID-19. J. Glob. Health 10:010332. doi: 10.7189/jogh. 10.010332

Reiter, K., Ventura, J., Lovell, D., Augustine, D., Barragan, M., Blair, T., et al. (2020). Psychological distress in solitary confinement: symptoms, severity, and prevalence in the United States, 2017-2018. Am. J. Publ. Health 110, S56-S62. doi: 10.2105/AJPH.2019.305375

Rosenbaum, S., Stubbs, B., Schuch, F., and Vancampfort, D. (2018). Exercise and Posttraumatic Stress Disorder. Handbuch Stressregulation und Sport. Berlin: Springer, 375-387. doi: 10.1007/978-3-662-49322-9_16

Rosenbaum, S., Vancampfort, D., Steel, Z., Newby, J., Ward, P. B., and Stubbs, B. (2015). Physical activity in the treatment of post-traumatic stress disorder: a systematic review and meta-analysis. Psychiatry Res. 230, 130-136. doi: 10. 1016/j.psychres.2015.10.017

Ryan, E. E., Rossi, M. D., and Lopez, R. (2010). The effects of the contractrelax-antagonist-contract form of proprioceptive neuromuscular facilitation stretching on postural stability. J. Strength Cond. Res. 24, 1888-1894. doi: 10.1519/JSC.0b013e3181ddad9d

Saloner, B., Parish, K., Ward, J. A., DiLaura, G., and Dolovich, S. (2020). COVID19 cases and deaths in federal and state prisons. JAMA 324, 602-603. doi: 10.1001/jama.2020.12528

Shalev, S. (2008). A Sourcebook on Solitary Confinement. London: Mannheim Centre for Criminology, London School of Economics. doi: 10.2139/ssrn. 2177495

Siu, G. K.-H., Lee, L.-K., Leung, K. S.-S., Leung, J. S.-L., Ng, T. T.-L., Chan, C. T.M., et al. (2020). Will a new clade of SARS-CoV-2 imported into the community spark a fourth wave of the COVID-19 outbreak in Hong Kong? Emerg. Microb. Infect. 9, 2497-2500. doi: 10.1080/22221751.2020.1851146

Spaaij, R., Broerse, J., Oxford, S., Luguetti, C., McLachlan, F., McDonald, B., et al. (2019). Sport, refugees, and forced migration: a critical review of the literature. Front. Sports Active Liv. 1:47. doi: 10.3389/fspor.2019.00047

Stade, K., Skammeritz, S., Hjortkjær, C., and Carlsson, J. (2015). "After all the traumas my body has been through, I feel good that it is still working."-basic body awareness therapy for traumatised refugees. Torture 25, 33-50.

Stephenson, J. (2020). COVID-19 pandemic poses challenge for jails and prisons. JAMA Health Forum 1:e200422. doi: 10.1001/jamahealthforum.2020.0422

Sternfeld, B., Ainsworth, B. E., and Quesenberry, C. Jr. (1999). Physical activity patterns in a diverse population of women. Prev. Med. 28, 313-323. doi: 10.1006/pmed.1998.0470

Trotter, R. T. II, Lininger, M. R., Camplain, R., Fofanov, V. Y., Camplain, C., and Baldwin, J. A. (2018). A survey of health disparities, social determinants of health, and converging morbidities in a county jail: a cultural-ecological assessment of health conditions in jail populations. Int. J. Environ. Res. Publ. Health 15:2500. doi: 10.3390/ijerph15112500

UNHCR (2020). The Refugee Brief 2020. Geneva: UNHCR.

Vogel, T., Brechat, P. H., Leprêtre, P. M., Kaltenbach, G., Berthel, M., and Lonsdorfer, J. (2009). Health benefits of physical activity in older patients: a review. Int. J. Clin. Pract. 63, 303-320. doi: 10.1111/j.1742-1241.2008.01957.x

Wallace, D., and Wang, X. (2020). Does in-prison physical and mental health impact recidivism? SSM Popul. Health 11:100569. doi: 10.1016/j.ssmph.2020. 100569

Wan, K., Chen, J., Lu, C., Dong, L., Wu, Z., and Zhang, L. (2020). When will the battle against novel coronavirus end in Wuhan: a SEIR modeling analysis. J. Glob. Health 10:011002. doi: 10.7189/jogh.10.011002

Wang, C., Horby, P. W., Hayden, F. G., and Gao, G. F. (2020). A novel coronavirus outbreak of global health concern. Lancet 395, 470-473. doi: 10.1016/S01406736(20)30185-9

WHO (2020). Coronavirus Disease (COVID-19) Pandemic 2020. Geneva: WHO.

WHO Regional Office for Europe (2020). Prisons and Health. Copenhagen: WHO Regional Office for Europe.

Wilder-Smith, A., and Freedman, D. O. (2020). Isolation, quarantine, social distancing and community containment: pivotal role for old-style public health measures in the novel coronavirus (2019-nCoV) outbreak. J. Travel Med. 27:taaa020. doi: $10.1093 / \mathrm{jtm} /$ taaa020

Xin, H., Karamehic-Muratovic, A., and Aydt Klein, N. (2017). Examining the effectiveness of physical activity on mental health among Bosnian refugees: a pilot study. Univ. J. Publ. Health 5, 76-84. doi: 10.13189/ujph.2017.050203

Conflict of Interest: The authors declare that the research was conducted in the absence of any commercial or financial relationships that could be construed as a potential conflict of interest.

Copyright (®) 2021 Ghram, Bragazzi, Briki, Jenab, Khaled, Haddad and Chamari. This is an open-access article distributed under the terms of the Creative Commons Attribution License (CC BY). The use, distribution or reproduction in other forums is permitted, provided the original author(s) and the copyright owner(s) are credited and that the original publication in this journal is cited, in accordance with accepted academic practice. No use, distribution or reproduction is permitted which does not comply with these terms. 